\title{
Causal judgment from contingency information: Relation between subjective reports and individual tendencies in judgment
}

\author{
PETER A. WHITE \\ Cardiff University, Cardiff, Wales
}

\begin{abstract}
In two experiments, participants made causal judgments from contingency information for problems with different objective contingencies. After the judgment task, the participants reported how their judgments had changed following each type of contingency information. Some reported idiosyncratic tendencies-in other words, tendencies contrary to those expected under associative-learning and normative rule induction models of contingency judgment. These idiosyncratic reports tended to be better predictors of the judgments of those who made them than did the models. The results are consistent with the view that causal judgment from contingency information is made, at least in part, by deliberative use of acquired and sometimes idiosyncratic notions of evidential value, the outcomes of which tend, in aggregate, to be highly correlated with the outcomes of normative procedures.
\end{abstract}

The investigation of how humans infer causal relations from contingency information has developed into one of the most important and intensively researched areas of the causal judgment literature. In this area, contingency information is defined as information about the occurrence or nonoccurrence of a certain effect in the presence or absence of a certain causal candidate. The accepted conventions for identifying the cells of a $2 \times 2$ contingency matrix are shown in Table 1.

There are currently two dominant accounts of how people make these judgments. One involves the use of rules of inference, and the other involves associative-learning mechanisms. Several rules of inference from contingency information have been investigated (Allan, 1993; Kao \& Wasserman, 1993), but recent research has been dominated by models constructed around the $\Delta P$ rule (Jenkins \& Ward, 1965; Ward \& Jenkins, 1965). This rule involves subtracting the proportion of occasions on which the effect occurs in the absence of a causal candidate from the proportion of occasions on which the effect occurs in the presence of that candidate. Subject to other conditions, the higher the product, the more likely that the candidate will be identified as a cause of the effect. The $\Delta P$ rule is the central component of the probabilistic contrast (PC) model (Cheng \& Novick, 1990, 1992) and the Power PC theory (Cheng, 1997); additional parts of the models specify the conditions under which a positive $\Delta P$ may or may not be interpreted as indicating a causal relation.

I am very grateful to John Pearce for much useful advice and information, to Edward A. Wasserman for valuable comments on an earlier draft of Experiment 1, and to Stephanie Bowen, Miranda Gay, and Rhiannon Davies for acting as experimenters. Correspondence concerning this article should be addressed to P. A. White, School of Psychology, Cardiff University, P. O. Box 901, Cardiff, Wales (e-mail: whitepa@ cardiff.ac.uk).
Under the associative-learning approach, causal judgment follows the accumulation of a record of experiences, forming an association between mental representations of a cue (or an action) and an outcome. When the cue is present and the outcome occurs, the associative bond tends to strengthen, unless it has already reached an asymptote. When the outcome does not occur in the presence of the cue, the associative bond tends to weaken. The stronger the associative bond, the more likely that the cue will be judged a cause of the outcome. The associative-learning approach has generally taken as its model the RescorlaWagner (R-W) model (Rescorla \& Wagner, 1972), and the application of the model to human causal judgment has been described by many authors (Allan, 1993; Shanks, 1993, 1995; Shanks \& Dickinson, 1987; Wasserman, Kao, Van Hamme, Katagiri, \& Young, 1996). A modified version of the model has also been proposed, in order to explain how causal judgment can change on instances when the cue is not present (Van Hamme \& Wasserman, 1994).

Both the associative-learning and the rule-based models make definite statements about how each type of contingency information ought to influence causal judgment. Under the $\Delta P$ rule, occurrences of the effect in the presence of the causal candidate (cell $a$ information) and nonoccurrences of the effect in the absence of the candidate (cell $d$ information) tend to increase $\Delta P$ and, therefore, tend to lead to an increase in causal judgment. Occurrences of the effect in the absence of the candidate (cell $c$ information) and nonoccurrences of the effect in the presence of the candidate (cell $b$ information) tend to decrease $\Delta P$ and, therefore, tend to lead to a decrease in causal judgment (or to an increase in the judgment that the candidate prevents the effect, if $\Delta P$ becomes noticeably negative). ${ }^{1}$ Under the R-W model, cell $a$ information tends to result in increased associative strength between 
Table 1

Conventional Identification of Cells in the $2 \times 2$ Contingency Table

\begin{tabular}{ccc}
\hline & \multicolumn{2}{c}{ Effect occurs } \\
\cline { 2 - 3 } Candidate Cause & Yes & No \\
\hline Present & $a$ & $b$ \\
Absent & $c$ & $d$ \\
\hline
\end{tabular}

the cue and the outcome (unless asymptote has already been reached) and, therefore, to an increase in causal judgment; for cell $b$ information, the opposite is the case. The associative strength of a cue-outcome relation does not change when the cue is absent (although the associative strength of background stimuli can change on such trials; Wasserman et al., 1996), so cell $c$ and cell $d$ information have little or no effect. The modified R-W model (Van Hamme \& Wasserman, 1994) predicts either an increase or no change for cell $a$ and cell $d$ information and either a decrease or no change for cell $b$ and cell $c$ information. The prediction of no change is permitted because the weight for a given type of information may be zero or insignificant.

To establish some terminological conventions for the rest of this paper, the term idiosyncratic will be used for reports or uses that do not conform to the prescriptions of either the $\Delta P$ rule or the associative-learning models. Idiosyncratic refers to reports or uses of a single type of information (e.g., cell $c$ information) and does not imply that the person in question deviated from the models on all types of information. The expression the models is used to refer collectively to the models that employ the $\Delta P$ rule, the $\mathrm{R}-\mathrm{W}$ model, and the modified $\mathrm{R}-\mathrm{W}$ model. Finally, the four types of contingency information are identified as follows: Cell $a$ information $=\mathrm{CO}$ (candidate present, outcome occurs); cell $b$ information $=\mathrm{C}-\mathrm{O}$ (candidate present, outcome does not occur); cell $c$ information $=-\mathrm{CO}$; cell $d$ information $=-\mathrm{C}-\mathrm{O}$.

The predictions of the models about the directional effects of the types of contingency information are particularly strong because the models are supposed to capture features of basic processes. ${ }^{2}$ The $\mathbf{R}-\mathrm{W}$ model appeals to basic learning mechanisms, and the case for the model as an account of human causal judgment rests, to a large extent, on the demonstration of several parallels with phenomena reported in animal learning experiments, such as blocking (Chapman, 1991; Chapman \& Robbins, 1990; Shanks, 1995). Cheng (1997) explicitly assumed "that the Power PC theory describes an innate component of the process of causal induction" (p. 397), and she defended this claim by arguing that the theory can explain animal learning phenomena, as well as causal induction by humans. Findings that humans use the types of contingency information in ways contrary to those prescribed would, therefore, be problematic for the models as accounts of human causal judgment. Evidence of this kind, particularly if there were significant individual differences, would favor the hypothesis that causal induction from contingency information is a feature of higher order cognition, not inbuilt processes of learning or induction, and that it draws on acquired notions of the evidential value of different types of contingency information. This will be termed the acquired notions hypothesis.

The predictions of the models, between them, account for two of the three possible outcomes on any given trial with any given type of information (increase, decrease, or no change); so, by chance alone, outcomes that violate the models' predictions should be in the minority. Furthermore, one would expect that even people judging according to relatively eccentric acquired notions would agree with the models on some things. For example, no one is likely to judge that an occurrence of the effect in the presence of a candidate cause reduces the likelihood that the candidate was the cause, in the absence of other information, such as preconceived beliefs. Under any hypothesis, therefore, idiosyncratic tendencies should be in the minority. By the same token, however, the fact that tendencies consistent with the models are in the majority does not count strongly in favor of the models, because that fact would hold even if the models were false. The ability of different hypotheses to account for the occurrence of idiosyncratic tendencies will help to decide which of them is superior.

However, the mere occurrence of a small number of idiosyncratic judgments would not be sufficient to decide the matter in favor of the acquired notions hypothesis. Small numbers of idiosyncratic judgments can occur for many reasons, including chance fluctuations in judgment and deliberate noncompliance with perceived demands, and neither of these would count against the models. The acquired notions hypothesis would only be favored, therefore, if the occurrence of idiosyncratic tendencies could be predicted. Since it is in the nature of idiosyncratic tendencies that they differ across individuals, the proper source of such predictions is the individuals themselves. The aim of the experiments reported below, therefore, is to assess whether participants' reports of how they used each of the types of contingency information will predict their own judgments better than the models will, when there is disagreement between them. If the participants' reports are better predictors, that would favor the acquired notions hypothesis over the $\Delta P$ rule, the $\mathrm{R}-\mathrm{W}$ model, and the modified $\mathrm{R}-\mathrm{W}$ model.

Although evidence of this kind has not previously been reported, some experiments have found evidence of idiosyncratic tendencies and subjective report accuracy. In one experiment using trial-by-trial presentation, participants appeared to treat cell $d$ information as disconfirmatory (Arkes \& Harkness, 1983, Experiment 7). Arkes and Harkness did not report whether the mean deviation observed was significantly different from zero or not, but it was both substantial ( -20.1 on a 101-point scale) and somewhat greater than that reported for cell $c$. This is an isolated finding: Most studies have found that cell $d$ information tends to be either neglected or treated as confirmatory (Allan, 1993; Cheng, 1997; Shanks, 1995). An- 
derson and Sheu (1995) found that individual differences in subjective reports were closely related to differences in utilization of different types of contingency information, but they did not look at idiosyncratic tendencies. Waldmann and Holyoak (1992) found evidence that judgments were affected by abstract world knowledge, supporting the acquired notions hypothesis, but later research by Shanks and Lopez (1996) cast doubt on their findings. White (1998) found evidence of idiosyncratic use of information, particularly for cells dealing with the absence of a possible cause and/or the nonoccurrence of the effect. Those experiments, however, presented stimulus information in tabulated summaries, and it is not clear whether the findings would generalize to the more usual trial-bytrial presentation method, in which information is presented one instance at a time.

The aim of the present research, therefore, is to investigate subjective reports systematically with trial-by-trial presentations involving one causal candidate, taking causal judgments after every trial so that changes in judgments can be recorded. Several separate problems are presented with different objective contingencies. The purpose of this is to test the hypothesis that the aggregate judgmental tendencies conform to the predictions of the $\Delta P$ rule and the $\mathrm{R}-\mathrm{W}$ model even in the presence of idiosyncratic information use by some participants. This is important to the case being made here, because, if the hypothesis is supported, it will show that findings of other experiments that appear to support those models do not necessarily imply that no idiosyncratic tendencies occurred in them.

\section{EXPERIMENT 1}

Experiment 1 was originally designed to investigate the effects of manipulating order of presentation of information on causal judgment in a trial-by-trial presentation. Four conditions were designed, comprising two pairs with identical contingencies. Within each pair, a critical block of eight trials was placed as the first eight trials in one condition and as the last eight in the other. In one pair, the critical block contained a high proportion of $\mathrm{CO}$ trials, and in the other, the critical block contained a high proportion of $\mathrm{C}-\mathrm{O}$ trials. Early versus late and $\mathrm{CO}$ versus $\mathrm{C}-\mathrm{O}$ were both within-subjects variables, so each participant took part in all four conditions, the order of presentation of which was randomized for each participant. The order and content of the remaining trials was controlled, and they contained equal numbers of confirmatory and disconfirmatory trials. For the two conditions with the high $\mathrm{CO}$ blocks, the contingency was $.67 / .5$, where the first number is $p_{(\mathrm{e} / \mathrm{c})}$, the probability of the effect occurring in the presence of the candidate cause, and the second number is $p_{(\mathrm{e} /-\mathrm{c})}$. For the two conditions with the high $\mathrm{C}-\mathrm{O}$ blocks, the contingency was $.33 / .5$. Unconditional $\Delta P=+.17$ and -.17 , respectively. The Appendix lists the order of trials in each condition.

Following pilot work, the experiment was modified for the purposes of the present research. This involved adding the structured debriefing procedure described in the Method section. The debriefing procedure was designed to elicit the reports, the content and accuracy of which are the main concerns of this experiment.

\section{Method}

Participants. The participants were 40 paid volunteer undergraduate students of subjects other than psychology. There were 27 women and 13 men.

Materials. The participants were initially presented with written instructions, which they were asked to read carefully:

Imagine that you work in a plant nursery and you are trying to work out whether a certain chemical preparation causes or prevents flowering in a certain kind of plant. You will be given information about a series of tests in which some plants were given the chemical and others were not. The information tells you whether each plant flowered or not. The information will be presented one plant at a time.

After seeing each piece of information, you should tell me your judgment of the likelihood that the chemical causes or prevents flowering in that kind of plant. You should do this by giving me a number from -100 to +100 .

+100 indicates that the chemical definitely causes flowering in that kind of plant.

-100 indicates that the chemical definitely prevents flowering in that kind of plant.

0 (zero) indicates that it has no effect either way.

You may use any number between -100 and +100 , depending on how likely you think it is that the chemical causes or prevents flowering.

All the problems presented information typed on $5 \times 3$ in. file cards, one card for each trial. Each problem was presented as concerning a different plant and a different chemical. On the first line of each card was the number of the plant. Each card in any given problem had a different number. Below that was a statement of whether the chemical was given to the plant or not. Below that was a statement of whether the plant flowered or not. Each problem consisted of 24 trials (cards).

Procedure. The experiment was run by experimenters blind to the aims and hypotheses of the experiment. The participants were run individually. The experimenter first gave the participant the written instructions. The participants were permitted to ask questions if they were uncertain about anything. The experimenter checked that the participant had understood the instructions and then presented a short practice run comprising eight cards, two of each kind. During this run, the participant was encouraged to ask questions if anything was not clear, and the experimenter checked that the participant's understanding of the instructions was correct. When the experimenter was satisfied and the participant was ready, the first of the four problems was presented. The problems were presented in random order, the order being randomized anew for each participant.

The initial step in presenting a problem was to place a card on the desk in front of the participant with the names of a fictitious chemical and a plant written on it. Different names were used for different problems. This was to ensure that the participant treated the four problems as independent. Before seeing any cards, the participant was then asked to make an initial judgment of the likelihood that the chemical caused or prevented flowering in that kind of plant. This was the baseline judgment. This and all subsequent judgments were made verbally by the participant and were recorded on paper by the experimenter. The first card was then placed on the table in front of the participant, and the participant was asked for a judgment. As soon as the participant made a judgment, the card was removed from view, and the participant was not permitted to change his or her judgment. The experimenter then recorded the judgment and 


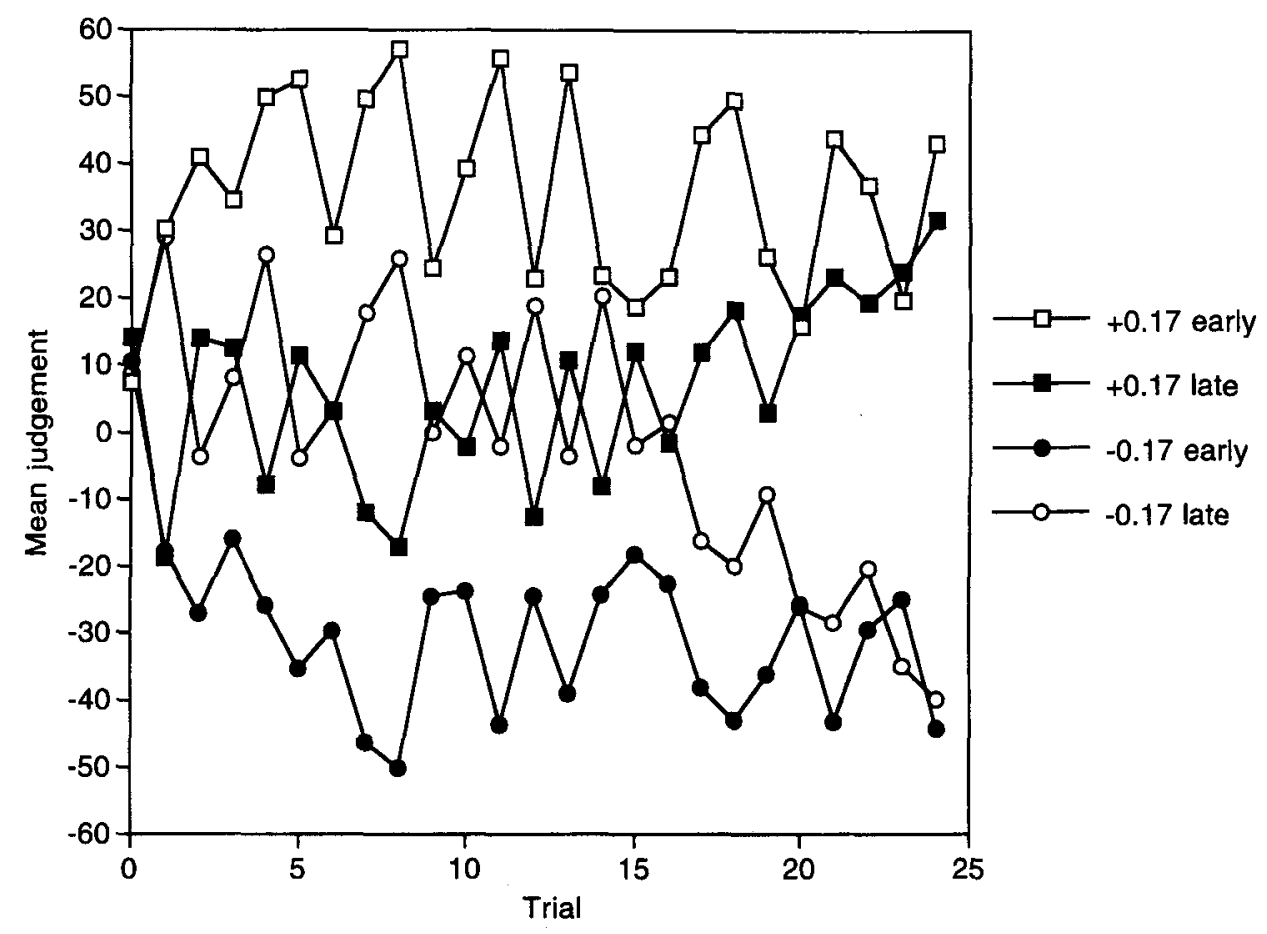

Figure 1. Mean judgments of causality across trials for each condition, Experiment 1.

presented the next card. This procedure was repeated until all the cards for the problem had been presented. At no time was the participant allowed to see the written record of his or her judgments.

After all four problems had been presented, a structured debriefing procedure was used. The participant was first asked whether everything had been O.K. or whether he or she had had any problems. The participant was then asked how he or she had been making the judgments. Following this, he or she was asked what effect each of the four types of information had had on the judgments. These are the key questions for the present experiment. The experimenter verbally described each kind of information in turn (e.g., "information that the chemical was given to the plant and the plant flowered" for $\mathrm{CO}$ information, and equivalent wording for the other three kinds) and recorded the participant's response. In most cases, the experimenter simply recorded "increase," "decrease," "no effect," or some combination of these. Other kinds of reports were recorded verbatim. Finally, the participant was asked whether there was anything else he or she could say about how he or she was doing the task. The participant was then paid and thanked. The participant was not informed of the aims and hypotheses of the experiment at this stage, for fear of contaminating future participants, but after the conclusion of the experiment, information was posted on a noticeboard designated for that purpose.

\section{Results and Discussion}

Means of causal judgments at each trial for each condition are shown in Figure 1. An analysis of variance (ANOVA) on the final judgments revealed that the participants successfully distinguished the two positive contingencies from the two negative contingencies $[F(1,39)=$ $202.19, p<.001]$. Neither the main effect of the order manipulation nor the interaction between the two variables was statistically significant. ${ }^{3}$
Table 2 lists all instances of idiosyncratic report. Closer to zero means a report that information of the given type led to the next judgment's being closer to zero: in other words, if the previous judgment had been positive there was a decrease in judgment, and if the previous judgment had been negative there was an increase in judgment. All reports not included in Table 2 conformed to one of the models, except that there were 10 instances of reports (by 5 different participants) that did not clearly indicate what predictions for judgment would follow. For example, 1 participant reported that $\mathrm{C}-\mathrm{O}$ and $-\mathrm{CO}$ information were "wild cards" (quotation from the experimenter's verbatim transcript), which does not clearly indicate how the participant thought the cards in question had been used.

Table 2 shows eight cases of idiosyncratic report involving 6 participants. Six cases involved $-\mathrm{CO}$ information, and two involved $-\mathrm{C}-\mathrm{O}$ information. In Table 2 , the word or does not indicate subjective uncertainty: The participants were reporting that one tendency occurred on some trials, and the other on others. Information about report accuracy is given in Table 3. Table 3 also reports the predictive accuracy of the modified R-W model. The modified $\mathrm{R}-\mathrm{W}$ model was used for this comparison because it makes more predictions for each information type (both decrease and no change for $-\mathrm{CO}$ and both increase and no change for $-\mathrm{C}-\mathrm{O}$ ) than do the other models and, therefore, provides a more stringent comparative test.

The key datum is whether a judgment following a particular type of information showed the direction of change 
Table 2

Idiosyncratic Reports, Experiment 1

\begin{tabular}{ccl}
\hline Participant & Information Type & \multicolumn{1}{c}{ Report } \\
\hline 9 & $-\mathrm{CO}$ & + or - \\
9 & $-\mathrm{C}-\mathrm{O}$ & + or - \\
12 & $-\mathrm{CO}$ & 0 or + \\
20 & $-\mathrm{CO}$ & + or - \\
27 & $-\mathrm{CO}$ & Closer to zero \\
33 & $-\mathrm{CO}$ & Closer to zero \\
35 & $-\mathrm{CO}$ & Closer to zero \\
35 & $-\mathrm{C}-\mathrm{O}$ & Closer to zero \\
\hline
\end{tabular}

Note- $+=$ increased judgment (use of information as confirmatory); $-=$ decreased judgment (use of information as disconfirmatory); $0=$ no effect.

predicted by a particular model. For example, if the model predicted an increase following $\mathrm{CO}$ information, was an increase actually observed after a particular $\mathrm{CO}$ trial? A change that conformed to the predictions of a model was called a hit, and a change that violated the predictions was called a miss. The numbers of hits and misses for the subjective reports and the modified $\mathrm{R}-\mathrm{W}$ model were tabulated for each participant. The resultant contingency tables violate the requirement that fewer than $20 \%$ of the cells should have an expected frequency $<5$, so $\chi^{2}$ could not be used (Siegel, 1956). Instead, the likelihood ratio statistic $G^{2}$ was used, which has the same distribution as $\chi^{2}$ (Tabachnik \& Fidell, 1989). With small numbers of observations, the chances of obtaining significant results for individuals were not great, but in two cases, the results were significant $(p<.05)$, and both favored the subjective reports.

On each trial, there were three possible outcomes: increase, no change, and decrease. The modified R-W model predicts either of two outcomes for any given trial: For example, for $\mathrm{CO}$ information, increase and no change are both hits as far as the modified $\mathrm{R}-\mathrm{W}$ model is concerned. Therefore, the chance success rate for the modified $\mathrm{R}-\mathrm{W}$ model is $66.7 \%$. The observed success rate of $68.7 \%$ is therefore $2.0 \%$ better than chance. Some of the subjective reports were consistent with two out of three possible outcomes, and some (the closer to zero rules) with only one. Putting it all together, the chance success rate for the subjective reports is $54.2 \%$, so the observed success rate of $81.2 \%$ is $27.0 \%$ better than chance expectation.

The most significant feature of the reports was their success in predicting increases following - $\mathrm{CO}$ information. The 6 participants made a total of 72 judgments following $-\mathrm{CO}$ information ( $3-\mathrm{CO}$ trials per problem $\times$ 4 problems per participant $\times 6$ participants). Of these, $22(30.6 \%)$ showed increases, and the participants' reports correctly predicted 21 of them $(95.5 \%)$. The one exception was an increase that violated the closer-to-zero rule reported by Participant 33. Across the other 34 participants, there were 53 instances of increase following $-\mathrm{CO}$ information, $13.0 \%$ of the relevant instances $(3 \times 4 \times 34=$ 408 instances). The mean number of instances of in- crease was significantly higher among the 6 participants whose reports included predictions of increase than among the remainder $[t(38)=2.20, p<.05]$. None of the models is able to predict this difference, because none of them predicts increases following $-\mathrm{CO}$ information. This finding, therefore, favors the acquired notions hypothesis.

The finding is all the more impressive because none of the 6 participants predicted that increase would occur following every instance of $-\mathrm{CO}$ information (see Table 2): Under the closer-to-zero rule, for example, increase was predicted to occur only when the previous judgment had been negative, which was roughly $50 \%$ of the time. The participants reporting this rule accurately predicted when a single judgment following - $\mathrm{CO}$ information would show an increase and when it would show a decrease. The apparent failure of Participant 35 was mainly due to several instances of zero change, not to getting the direction of change wrong.

In summary, in this experiment eight reports by 6 participants were inconsistent with the models. Over all eight cases, the modified $\mathrm{R}-\mathrm{W}$ model performed at a level of accuracy close to chance expectation, whereas the subjective reports were over those cases considerably more accurate than chance expectation. Six participants who reported idiosyncratic use of $-\mathrm{CO}$ information showed considerable success at predicting instances of increase in judgment, and such instances were significantly more frequent among those 6 than among the remaining 34 . Thus, although the modified $\mathrm{R}-\mathrm{W}$ model is consistent with much of the evidence of actual changes in judgment, the model does not account for the fact that increases following $-\mathrm{CO}$ information were more frequent for participants whose reports included predictions of increase than for those whose reports did not.

Having said that, the quantity of evidence is small; so, before drawing conclusions with any confidence, it is necessary to obtain more evidence. The main aim of Experiment 2 was to look more systematically at two kinds of idiosyncratic report: first, reports of increase following $-\mathrm{CO}$ information and of decrease following $-\mathrm{C}-\mathrm{O}$ information and second, reports of use of the closer-tozero rule. If these reports accurately represent participants' knowledge of what they were doing, frequencies

Table 3

Conformity of Observed Judgments to Subjective Reports and Modified Rescorla-Wagner (R-W) Model, Experiment 1

\begin{tabular}{|c|c|c|c|c|}
\hline \multirow[b]{2}{*}{ Participant } & \multicolumn{2}{|c|}{$\%$ Conformity to Rule } & \multirow[b]{2}{*}{$G^{2}$} & \multirow[b]{2}{*}{$p$} \\
\hline & Subjective & Modified R-W & & \\
\hline $9(-\mathrm{CO})$ & 100.0 & 50.0 & 4.49 & $<.05$ \\
\hline $9(-\mathrm{C}-\mathrm{O})$ & 91.7 & 50.0 & 2.37 & n.s. \\
\hline $12(-\mathrm{CO})$ & 100.0 & 58.3 & 3.59 & n.s. \\
\hline $20(-\mathrm{CO})$ & 83.3 & 83.3 & 0.00 & n.s. \\
\hline $27(-\mathrm{CO})$ & 100.0 & 50.0 & 4.49 & $<.05$ \\
\hline $33(-\mathrm{CO})$ & 91.7 & 75.0 & 0.21 & n.s. \\
\hline $35(-\mathrm{CO})$ & 58.3 & 100.0 & 3.59 & n.s. \\
\hline $35(-\mathrm{C}-\mathrm{O})$ & 25.0 & 83.3 & 3.82 & n.s. \\
\hline Mean & 81.2 & 68.7 & & \\
\hline
\end{tabular}


Table 4

Frequencies of Types of Contingency Information, Experiment 2

\begin{tabular}{lcccc}
\hline & \multicolumn{4}{c}{ Condition } \\
\cline { 2 - 5 } Information Type & $.75 / .25$ & $.58 / .42$ & $.42 / .58$ & $.25 / .75$ \\
\hline $\mathrm{CO}$ & 9 & 7 & 5 & 3 \\
$\mathrm{C}-\mathrm{O}$ & 3 & 5 & 7 & 9 \\
$-\mathrm{CO}$ & 3 & 5 & 7 & 9 \\
$-\mathrm{C}-\mathrm{O}$ & 9 & 7 & 5 & 3 \\
\hline
\end{tabular}

of changes of judgment of the kind in question should be higher for the participants who report them than for those who do not. For those who report using the closer-to-zero rule, frequencies of changes of judgment conforming to that rule should be higher than frequencies conforming to the modified $\mathrm{R}-\mathrm{W}$ model. Running another experiment also provides an opportunity to systematize the subjective report procedure, with the aim of obtaining more information from participants.

\section{EXPERIMENT 2}

\section{Method}

Participants. The participants were 53 volunteer first-year undergraduate students of psychology, participating in return for course credit. There were 35 women and 18 men.

Materials. Scenario information and instructions for the causa judgment task were the same as those for Experiment 1. Four problems were used with contingencies of $.75 / .25, .58 / .42, .42 / .58$, and $.25 / .75$. Unconditional $\Delta P=+.5,+.167,-.167$, and -.5 , respectively. Frequencies of instances within problems are shown in Table 4: The total across problems is 24 of each type. In the experimental trials, the cards were randomly ordered within problems, and a new random order was generated for each participant. Each participant received all four problems, and problem order was randomized for each individual.

Materials for the subjective report task were redesigned for this experiment. The participant received a five-page questionnaire. Each of the first four pages began as follows (using $\mathrm{CO}$ information as an example):

When a card had the following information:

\section{The chemical was given to the plant The plant flowered}

what effect did it have on your judgment? Please write here as clearly and accurately as you can what sort of effect it had.

Wording on the other three pages was similar but was modified in accordance with the type of information in question.

Beneath this, a space was left for the participant's free report. Beneath this, the participant was instructed to circle one of four response options for each of the following four statements:

1. It made me increase my judgment (made my judgment more positive).

2. It made me decrease my judgment (made my judgment more negative).

3. It had no effect-my judgment did not change.

4. It made my judgment closer to zero. (In other words, if your previous judgment had been less than zero it made you increase your judgment and if your previous judgment had been more than zero it made you decrease your judgment.)

The four response options were never, sometimes, most times, and every time. These appeared immediately beneath each statement.
The fifth page simply asked the participant whether he or she could say anything else about how he or she was making the judgments. Space was provided for his or her report.

Procedure. The procedure was similar to that of Experiment 1. In this experiment, the practice run contained 24 trials. For both the practice run and the four main problems, the cards were randomly ordered, and a new random order was generated for each participant. The experimenter recorded the order of presentation. After the four main problems had been completed, the participant was given the subjective report questionnaire. The first four pages of the questionnaire were randomly ordered and were randomized independently for each participant. When the participant had completed the questionnaire, he or she was thanked and debriefed. All the other details of the procedure were the same as those for Experiment 1 .

\section{Results and Discussion}

Means of causal judgments at each trial for each condition are shown in Figure 2. An ANOVA on the final judgments revealed that the participants successfully distinguished the four contingencies $[F(3,156)=83.23, p<$ $.001]$. Post hoc comparisons, using the Newman-Keuls test, revealed that all the contingencies were significantly different from each other $(p<.01$ in all cases).

Responses to the statements in the questionnaire were analyzed. For $\mathrm{CO}$ and $\mathrm{C}-\mathrm{O}$ information, as in Experiment 1 , responses generally conformed to normative expectations. For - $\mathrm{CO}$ information, the participants were divided into two groups on the basis of their responses to the increase option: those who endorsed "sometimes," "most times," or "every time" ( $n=19$, labeled the yes group) and the remainder ( $n=34$, the no group). The actual mean number of increases following - $\mathrm{CO}$ information was 4.21 for the yes group and 2.00 for the no group. These two means were compared, using an ANOVA, and a significant difference was found $[F(1,51)=5.53, p<$ $.05]$. Thus, those who reported idiosyncratic information use showed evidence of more idiosyncratic information use than those who did not. The actual mean of 4.21 is not high, but the group may have included some who reported "sometimes" merely because they were avoiding the extreme response options. The no group includes some who reported themselves as using the closer-to-zero rule (see below). If those are excluded, the mean for this group falls to 1.17

For $-\mathrm{C}-\mathrm{O}$ information, the participants were divided into two groups on the basis of their responses to the decrease option: those who endorsed "sometimes," "most times," or "every time" ( $n=23$, labeled the yes group) and the remainder ( $n=30$, the no group). The actual mean number of increases following $-\mathrm{C}-\mathrm{O}$ information was 4.43 for the yes group and 2.03 for the no group. These two means were compared, using an ANOVA, and a significant difference was found $[F(1,51)=5.20, p<$ $.05]$. Again, those who reported idiosyncratic information use showed evidence of more idiosyncratic information use than those who did not. If those who reported themselves as using the closer-to-zero rule are excluded from the no group, the mean falls to 1.22 . 


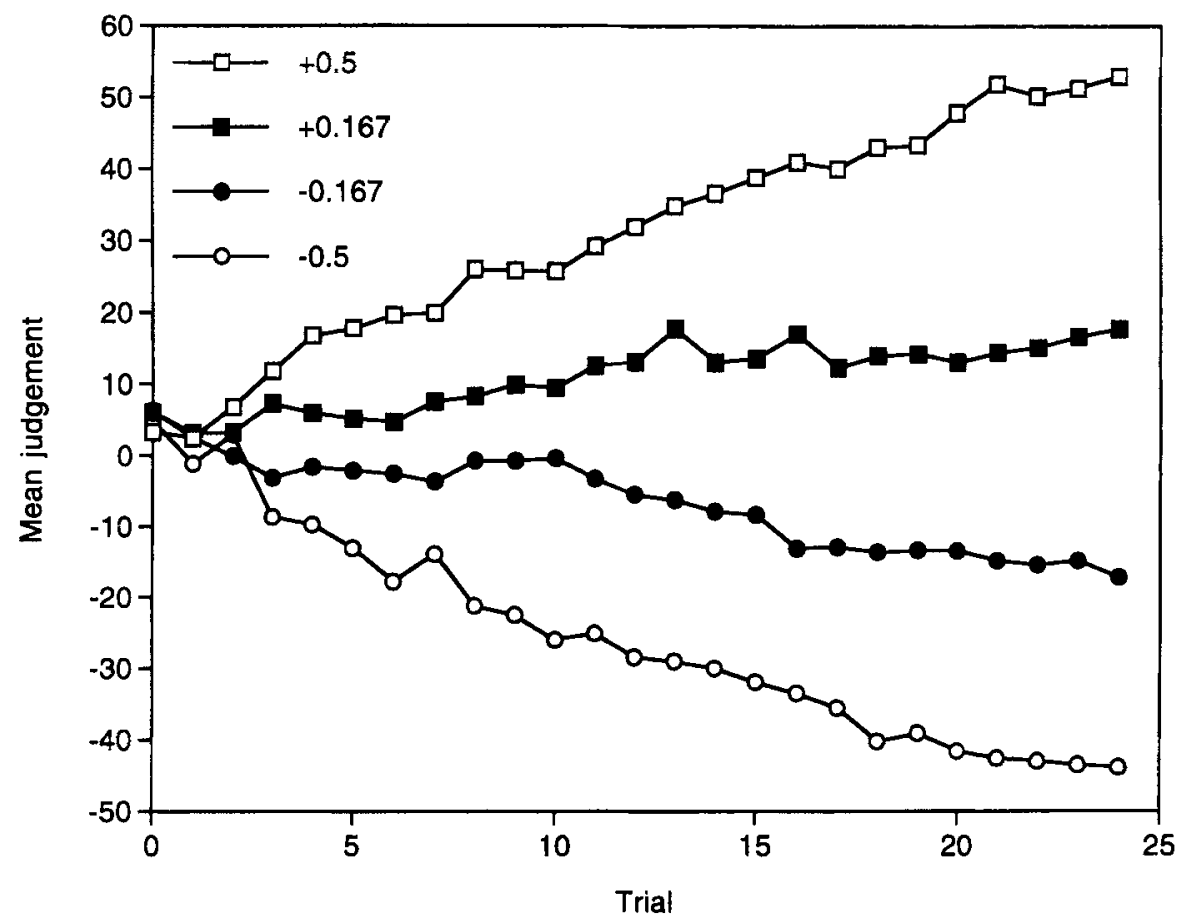

Figure 2. Mean judgments of causality across trials for each condition, Experiment 2.

Identifying participants who report themselves as using the closer-to-zero rule is not straightforward, because some people may not have appreciated that both halves of the statement describing the rule had to hold for their judgments to count as conforming to the rule. Such individuals would endorse the rule for themselves, although they were not in fact using it. For this reason, a stringent two-stage procedure was used to identify those participants who reported using the closer-to-zero rule under the intended interpretation of that statement. In the first stage, all who endorsed "most times" or "every time" for the closer-to-zero rule were selected. In the second stage, those whose free reports unambiguously contradicted their endorsement of the closer-to-zero rule were excluded.

For - $\mathrm{CO}$ information, this procedure identified 5 participants as using the closer-to-zero rule. The mean number of changes in judgment conforming to the rule for these 5 participants was 20.40 (the maximum possible number being 24 ), whereas the mean for the other 48 participants was 9.29. These means were compared, using an ANOVA, and a significant difference was found $[F(1,51)=$ $30.09, p<.001]$. For the 5 selected participants, the mean number of changes in judgment conforming to the modified R-W model was found to be 16.20 . This was compared with the mean number conforming to the closer-tozero rule, and the difference was found to be marginally significant $[F(1,4)=5.80, p=.07]$.

For $-\mathrm{C}-\mathrm{O}$ information, the procedure identified 6 participants as using the closer-to-zero rule. The mean number of changes in judgment conforming to the rule for these 6 participants was 21.00 , whereas the mean for the other 47 participants was 7.00. These means were compared, using an ANOVA, and a significant difference was found $[F(1,51)=72.46, p<.001]$. For the 6 selected participants, the mean number of changes in judgment conforming to the modified $\mathrm{R}-\mathrm{W}$ model was found to be 14.17. This was compared with the mean number conforming to the closer-to-zero rule, and a significant difference was found $[F(1,4)=109.16, p<.001]$.

In summary, those participants reporting increase at least sometimes for - $\mathrm{CO}$ showed higher frequencies of increase than did the other participants. Those participants reporting decrease at least sometimes for $-\mathrm{C}-\mathrm{O}$ showed higher frequencies of decrease than did the other participants. Those participants reporting use of the closer-tozero rule showed higher frequencies of changes conforming to the rule than did the other participants. They also showed higher frequencies of changes conforming to the closer-to-zero rule than to the modified $\mathrm{R}-\mathrm{W}$ model, for both $-\mathrm{CO}$ and $-\mathrm{C}-\mathrm{O}$ information. All of these results favor the acquired notions hypothesis.

Another way of looking at the results is to compute the mean magnitude of change for each type of contingency information across the 24 trials of each type received by each participant. For this purpose, those participants reporting idiosyncratic rule use (those reporting increase at least sometimes for $-\mathrm{CO}$, those reporting decrease at least sometimes for $-\mathrm{C}-\mathrm{O}$, and those identified as using the closer-to-zero rule for at least one type of information) were separated from the rest, and mean magnitudes 
Table 5

Mean Magnitudes of Change for Each Type of Contingency Information, Experiment 2

\begin{tabular}{lrrrr}
\hline & \multicolumn{4}{c}{ Information Type } \\
\cline { 2 - 5 } Subgroup & $\mathrm{CO}$ & $\mathrm{C}-\mathrm{O}$ & $-\mathrm{CO}$ & $-\mathrm{C}-\mathrm{O}$ \\
\hline Idiosyncratics & +13.23 & -9.18 & -2.04 & -2.42 \\
Normatives & +8.84 & -7.44 & -5.36 & +3.65 \\
All & +11.16 & -8.36 & -3.60 & +0.44 \\
\hline
\end{tabular}

of change were calculated for this subgroup $(n=28$, called the idiosyncratics) and for the remainder $(n=25$, called the normatives). Means are reported in Table 5.

Idiosyncratics and normatives were compared within each information type, using the $t$ test for independent means [for CO information, $t(51)=1.56$, n.s. $(p>.1)$; for $\mathrm{C}-\mathrm{O}$ information, $t(51)=0.86$, n.s.; for $-\mathrm{CO}$ information, $t(51)=2.23, p<.05$; for $-\mathrm{C}-\mathrm{O}$ information, $t(51)=1.98, p=.053]$. The mean for $-\mathrm{C}-\mathrm{O}$ information in the idiosyncratic group was negative, which is the counternormative direction. That mean, however, owes a good deal to 1 participant with a mean change of -75.42 , the next lowest mean change being -8.33 . If that outlier is removed from the data, the mean becomes +0.29 , and the comparison with the normatives is statistically significant $[t(50)=3.02, p<.01]$.

In summary, then, the mean magnitude of change among the idiosyncratics was significantly less negative for $-\mathrm{CO}$, and significantly less positive for $-\mathrm{C}-\mathrm{O}$, than that among the normatives, with no significant differences for the other two types. There were, in all, 7 participants for whom the mean change for - $\mathrm{CO}$ information was positive, and all 7 were in the idiosyncratic group. There were 8 participants for whom the mean change for $-\mathrm{C}-\mathrm{O}$ information was negative, and all 8 were in the idiosyncratic group. Thus, those participants who reported idiosyncratic rules for $-\mathrm{CO}$ and/or $-\mathrm{C}-\mathrm{O}$ information did tend to differ from normatives in the direction of more idiosyncratic responding, but only for those two information types. This is further evidence that idiosyncratic responding not only occurs but is predicted by participants' reports. $^{4}$

\section{Additional Findings}

Several participants made idiosyncratic reports different from those tested above. Nine participants reported a total of 15 unambiguous conditional rules-for example, Participant 11 for $\mathrm{C}-\mathrm{O}$ information reported decrease, but no change if there had been a lot of $\mathrm{CO}$ trials. These rules predicted particular directions of correlation between information type and judgmental tendency. For example, Participant 11 's rule predicted that there should be a higher proportion of decreases following $\mathrm{C}-\mathrm{O}$ information in problems with fewer $\mathrm{CO}$ trials. This is the opposite of what the associative-learning models would predict. Analysis revealed that 14 out of 15 correlations were in the direction predicted by the participants' reports (mean $r=.73$ ), and only 5 out of 15 were in the direction predicted by the normative models. The difference between the two success rates is statistically significant $\left[\chi^{2}(1)=11.62, p<.01\right]$.

Eight participants reported using exact quantitative rules (e.g., +10 scale points each time) for one or more types of information. Agreement between these rules and actual changes in judgment was very high, being $100 \%$ for 4 of the 8 and no lower than $85 \%$ for any of them.

Finally, 32 participants $(60.4 \%)$ spontaneously reported using a particular method of judgment. Ten participants reported making judgments by counting numbers of instances of each type. Nine participants reported trying to remember or recall information without explicitly mentioning counting instances. Eleven participants reported adding to or subtracting from their previous judgment. Two participants reported what might be averaging processes. Space limitations preclude further investigation of these reports, but the possibility that they describe higher order processes of causal judgment, using acquired beliefs, may be worthy of further investigation.

\section{GENERAL DISCUSSION}

These experiments have revealed abundant evidence of idiosyncratic information use. The evidence takes the form of significant accuracy in reports of information use and superior accuracy of idiosyncratic reports over the predictions of the models. In Experiment 1, those participants making idiosyncratic reports of increase following $-\mathrm{CO}$ information showed more instances of increases following $-\mathrm{CO}$ information than did other participants, and there was also evidence that their reports were more accurate than the predictions of the models. In Experiment 2, this finding was replicated. The same was also found for those participants making idiosyncratic reports of decrease following $-\mathrm{C}-\mathrm{O}$ information. Changes in judgment by participants who reported using the closer-to-zero rule also conformed to that rule more than did those of other participants, and the rule predicted changes in judgment for those participants better than did the models. Those participants reporting conditional rules also exhibited patterns of judgment that conformed to those rules and, in most cases, went against what associative-learning models would predict.

Under the hypothesis that people judge causal relations from contingency information by either some version of associative learning or some process of induction involving or modelled by the $\Delta P$ rule, an increase in causal judgment following - $\mathrm{CO}$ information, a decrease in causal judgment following $-\mathrm{C}-\mathrm{O}$ information, closerto-zero tendencies following both types of information, and judgmental patterns conforming to most of the reported conditional rules are not predicted to occur. The idiosyncratic reports obtained in these two experiments show not just a level but a specific kind of accuracy that is beyond the explanatory scope of the associative-learning and $\Delta P$-based models, and therefore favor a hypothesis under which causal judgment from contingency informa- 


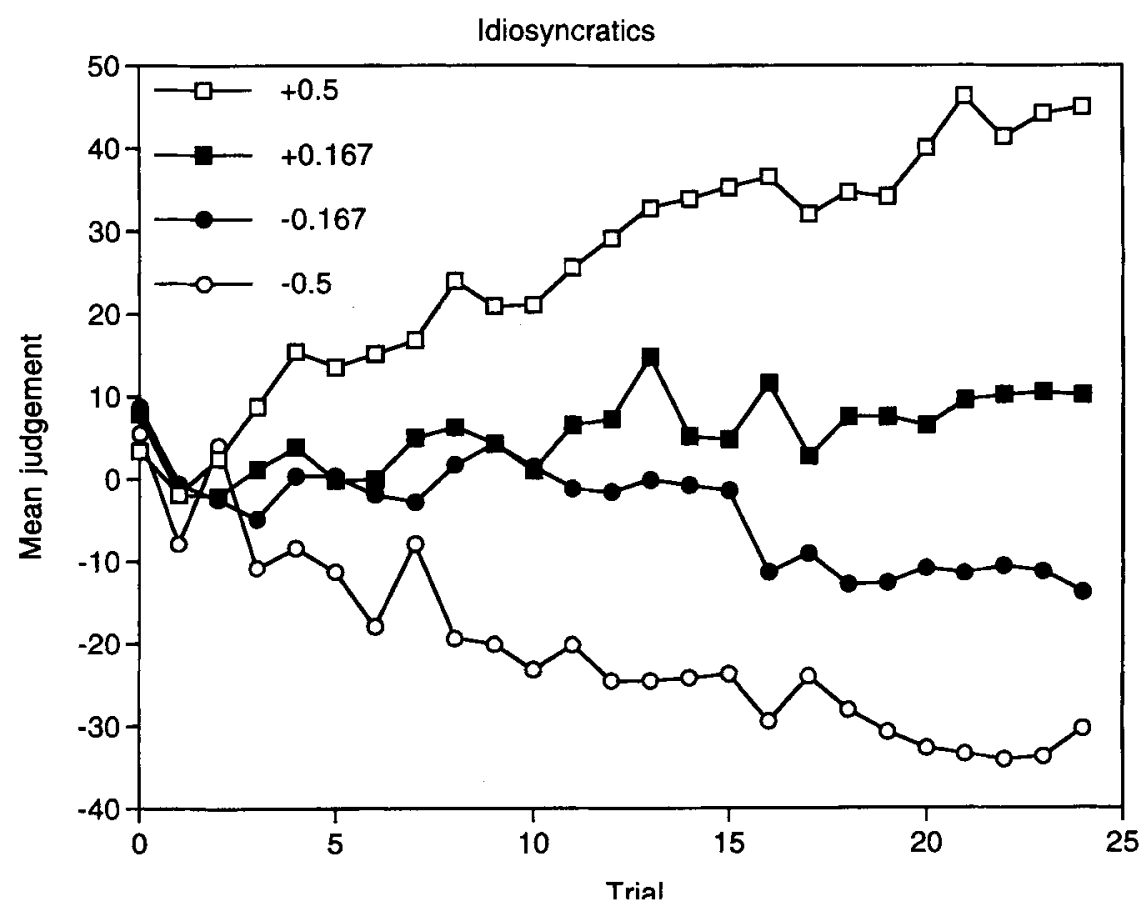

Figure 3. Acquisition curves for participants reporting idiosyncratic rules, Experiment 2.

tion is made by the application of acquired notions of evidential value in some process of higher order cognition.

The total number of participants making at least one idiosyncratic report in Experiment 2 (increase following $-\mathrm{CO}$, decrease following $-\mathrm{C}-\mathrm{O}$, or closer to zero) was $28,53 \%$ of the total participants, and this does not include those who reported conditional rules with implications for judgment opposite to those of the models. Even if we assume that half of those reporting increase following $-\mathrm{CO}$ or decrease following $-\mathrm{C}-\mathrm{O}$ were merely avoiding the extreme response "never," the total would still be $23,43 \%$ of the total participants. Since the evidence shows significant accuracy in those reports, it would appear that idiosyncratic tendencies in causal judgments from contingency information are not rare. They have not been commonly observed, because the kind of evidence that would reveal them has not been sought.

The idiosyncratic rules have been expressed in terms dictated largely by the materials and measures used in the present research. The closer-to-zero rule, for example, is described with reference to the present rating scale, which uses zero as a neutral center point. If these rules represent general notions of evidential value, it should be possible to describe them in a more abstract way. However, the correct abstract form of the rule would depend on the underlying concepts possessed by its users. What concept of evidential value does the closer-to-zero rule embody, for example? One possibility is that the type of information for which the rule is reported is viewed as weakening the link between the causal candidate and the effect--in other words, making it less likely that there is any relation between the candidate and the effect. Under that in- terpretation, the closer-to-zero rule would represent an application of a notion of weakening to the experimental materials. If that is the case, the lay understanding of the evidential value of contingency information for causal judgment may encompass a wider array of notions than just confirming and disconfirming. More research on the range of such notions people possess could shed much new light on the ways in which people make causal judgments from contingency information.

The case for the models as accounts of causal judgment rests largely on the abundant evidence for the sensitivity of judgments to objective differences between contingencies and for cue interaction effects, such as blocking (Chapman, 1991; Chapman \& Robbins, 1990; Cheng, 1997; Shanks, 1995; Shanks, Lopez, Darby, \& Dickinson, 1996; Van Hamme \& Wasserman, 1994; Wasserman et al., 1996). If participants are judging in accordance with acquired and sometimes idiosyncratic notions of the evidential value of contingency information for causal judgment, how could this account for the occurrence of phenomena such as blocking in human causal judgment and for the evidence that causal judgments are sensitive to actual variations in contingencies between problems, as in the results of the present experiments (Figures 1 and 2)?

Part of the explanation is that judgments generated by idiosyncratic rules tend to be highly correlated with those generated by rules regarded by many as normative, such as $\Delta P$ (McKenzie, 1994). McKenzie ran a computer simulation, using 6.25 million $2 \times 2$ matrices, independently varying each of the four cell values between 1 and 50 and generating output for a variety of judgmental rules. The rules were all highly correlated with each other and with 


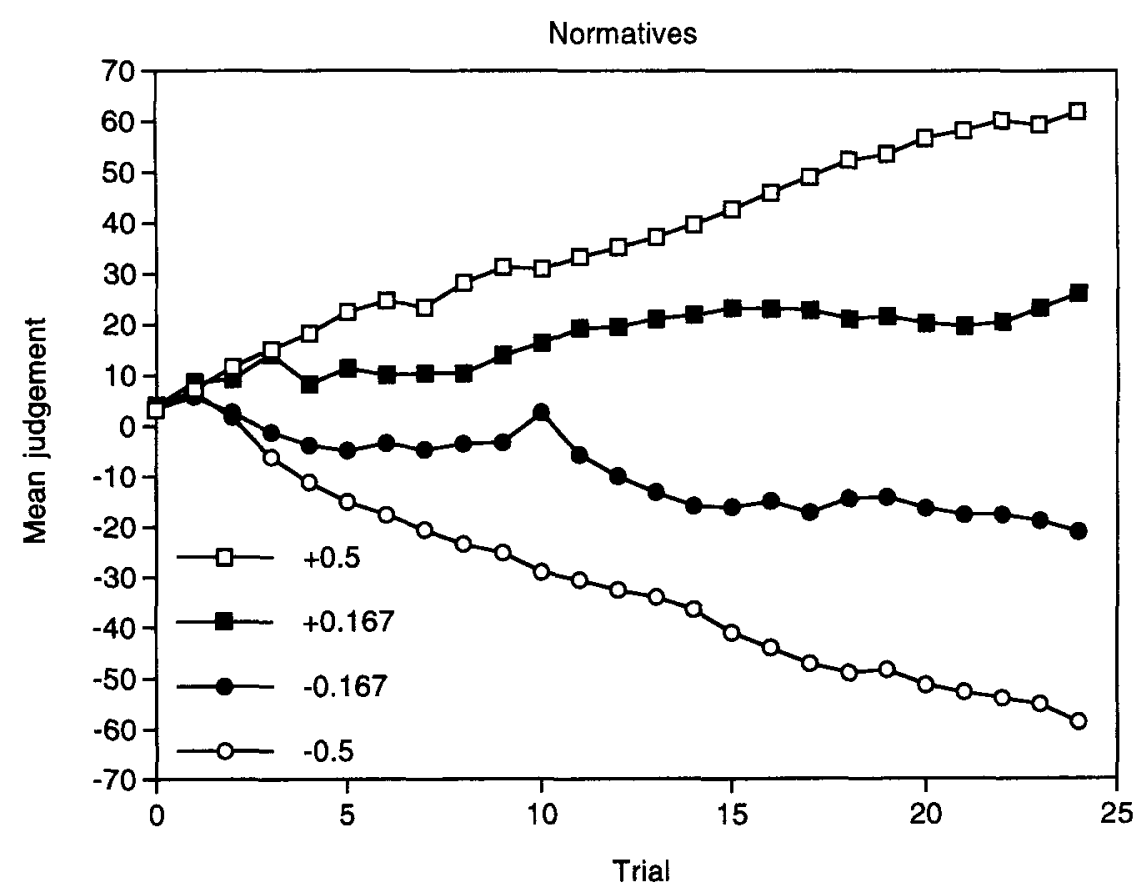

Figure 4. Acquisition curves for participants reporting normative rules, Experiment 2.

a normative rule (the $\phi$ coefficient, which was almost but not quite perfectly correlated with the $\Delta P$ rule). This implies that similar judgmental phenomena would be produced by many different rules.

The other part of the explanation is that idiosyncratic tendencies are in the minority: Even participants reporting idiosyncratic rules for both $-\mathrm{CO}$ and $-\mathrm{C}-\mathrm{O}$ information tended to report normative use of $\mathrm{CO}$ and $\mathrm{C}-\mathrm{O}$ information. This means that the effects of idiosyncratic rules that do not correlate with those of normative rules will tend to be outweighed by the combined effects of normative rules and idiosyncratic rules that do correlate with those of normative rules. This implies that participants using acquired notions will make judgments that tend to produce the effects predicted by the models, such as accurate discrimination between different contingencies and cue interaction effects. Evidence of those effects is, therefore, consistent both with the models and with the acquired notions hypothesis.

The present results support that reasoning. For Experiment 1 , final judgments were compared across problems for the 6 participants that were identified in Table 2 as reporting idiosyncratic rules, and, as for the sample as a whole, this group of 6 succeeded in distinguishing the two positive contingencies from the two negative contingencies [ +.17 early vs. -.17 early, $t(5)=9.85, p<.001$; +.17 early vs. -.17 late, $t(5)=9.08, p<.001 ;+.17$ late vs. -.17 early, $t(5)=7.32, p<.001 ;+.17$ late vs. -.17 late, $t(5)=6.65, p<.01]$. There was no significant difference between the two positive contingencies $[t(5)=0.13]$ or between the two negative contingencies $[t(5)=1.08]$.
For Experiment 2, changes in mean judgments across trials were calculated for the idiosyncratics, and the results are shown in Figure 3. An ANOVA was carried out on the idiosyncratics' final judgments, and a significant result was found $[F(3,27)=23.00, p<.001]$. Post hoc comparisons with the Newman-Keuls test revealed that all the contingencies were significantly different from each other: thus, the idiosyncratics collectively succeeded in distinguishing the different objective contingencies. Changes in mean judgments across trials were also calculated for the normatives, and the results are shown in Figure 4. Not surprisingly, an ANOVA also yielded a significant effect for this subgroup $[F(3,24)=$ $96.01, p<.001]$, and post hoc comparisons revealed significant differences between all four contingencies.

Final judgments, however, appeared to be less extreme for the idiosyncratics than for the normatives in all four cases. Within each condition, final judgments for the two subgroups were compared [in the +.5 condition, $t(51)=$ $1.86, p=.07$; in the +.167 condition, $t(51)=1.77, p=.08$; in the -.167 condition, $t(51)=0.97$, n.s.; in the -.5 condition, $t(51)=2.79, p<.01]$. The difference was, therefore, statistically significant in one condition and marginally so in two others. Idiosyncratic tendencies that do not correlate with normative tendencies might be outweighed by the rest, but these findings suggest that their influence, in terms of reduced sensitivity to differences in objective contingencies, is not completely negligible.

Overall, then, the evidence supports the argument that a group of participants judging in different ways, some of them very idiosyncratic, will give a close enough ap- 
proximation to the performance of the models to produce the judgmental phenomena predicted by them. Therefore, the net effect of having a mixture of participants of the sort observed here will be judgmental phenomena that match those predicted by the models. Idiosyncratic tendencies, such as use of the closer-to-zero rule, may, therefore, have occurred among a proportion of the participants in other studies of human causal judgment. Neither the evident ability of people to distinguish objectively different contingencies nor the occurrence of cue interaction effects favors the models over the acquired notions hypothesis: Both are predicted by both points of view. However, only the acquired notions hypothesis can explain the evidence found here of idiosyncratic judgmental tendencies and of close matches between judgmental tendencies and retrospective reports made about them.

\section{REFERENCES}

ALLAN, L. G. (1993). Human contingency judgements: Rule based or associative? Psychological Bulletin, 114, 435-448.

Anderson, J. R., \& Sheu, C.-F. (1995). Causal inferences as perceptual judgments. Memory \& Cognition, 23, 510-524.

ARKES, H. R., \& HARKNESS, A. R. (1983). Estimates of contingency between two dichotomous variables. Journal of Experimental Psychology: General, 112, 117-135.

Chapman, G. B. (1991). Trial order affects cue interaction in contingency judgment. Journal of Experimental Psychology: Learning, Memory, \& Cognition, 17, 837-854.

Chapman, G. B., \& Robbins, S. J. (1990). Cue interaction in human contingency judgment. Memory \& Cognition, 18, 537-545.

Cheng, P. W. (1997). From covariation to causation: A causal power theory. Psychological Review, 104, 367-405.

Cheng, P. W., \& Novick, L. R. (1990). A probabilistic contrast model of causal induction. Journal of Personality \& Social Psychology, 58, 545-567.

CHENG, P. W., \& Novick, L. R. (1992). Covariation in natural causal induction. Psychological Review, 99, 365-382.

JENKINS, H. M., \& WARD, W. C. (1965). Judgement of contingency between responses and outcomes. Psychological Monographs, 79 (Whole No. 10).

KaO, S.-F., \& Wasserman, E. A. (1993). Assessment of an information integration account of contingency judgment with examination of subjective cell importance and method of information presentation. Journal of Experimental Psychology: Learning, Memory, \& Cognition, 19, 1363-1386.

MARR, D. (1982). Vision. New York: Freeman.

MCKENZIE, C. R. M. (1994). The accuracy of intuitive judgment strategies: Covariation assessment and Bayesian inference. Cognitive Psychology, 26, 209-239.

RESCORLA, R. A., \& WAGNER, A. R. (1972). A theory of Pavlovian conditioning: Variations on the effectiveness of reinforcement and nonreinforcement. In A. H. Black \& W. F. Prokasy (Eds.), Classical conditioning II: Current research and theory (pp. 64-99). New York: Appleton-Century-Crofts.

ShaNKS, D. R. (1993). Human instrumental learning: A critical review of data and theory. British Journal of Psychology, 84, 319-354.

SHANKs, D. R. (1995). The psychology of associative learning. Cambridge: Cambridge University Press.

Shanks, D. R., \& Dickinson, A. (1987). Associative accounts of causality judgement. In G. H. Bower (Ed.), The psychology of learning and motivation (Vol. 21, pp. 229-261). New York: Academic Press.

Shanks, D. R., \& Lopez, F. J. (1996). Causal order does not affect cue selection in human associative learning, Memory \& Cognition, 24, $511-522$

Shanks, D. R., Lopez, F. J., Darby, R. J., \& Dickinson, A. (1996). Distinguishing associative and probabilistic contrast theories of human contingency judgment. In D. R. Shanks, K. J. Holyoak, \& D. L. Medin (Eds.), The psychology of learning and motivation: Vol. 34. Causal learning (pp. 265-311). San Diego: Academic Press.

SIEGEL, S. (1956). Nonparametric statistics for the behavioral sciences. London: McGraw-Hill.

TABACHNIK, B. G., \& Fidell, L. S. (1989). Using multivariate statistics (2nd ed.). New York: Harper \& Row.

VAN HAMme, L. J., \& Wasserman, E. A. (1994). Cue competition in causality judgments: The role of nonrepresentation of compound stimulus elements. Learning \& Motivation, 25, 127-151.

Waldmann, M. R., \& Holyoak, K. J. (1992). Predictive and diagnostic learning within causal models: Asymmetries in cue competition. Journal of Experimental Psychology: General, 121, 222-236.

WARD, W. C., \& JENKINS, H. M. (1965). The display of information and the judgment of contingency. Canadian Journal of Psychology, 19, 231-241.

Wasserman, E. A., KaO, S.-F., Van Hamme, L. J., Katagiri, M., \& Young, M. E. (1996). Causation and association. In D. R. Shanks, K. J. Holyoak, \& D. L. Medin (Eds.), The psychology of learning and motivation: Vol. 34. Causal learning (pp. 207-264). San Diego: Academic Press.

WHITE, P. A. (1998). Causal judgement: Use of different types of contingency information as confirmatory and disconfirmatory. European Journal of Cognitive Psychology, 10, 131-170.

\section{NOTES}

1. These tendencies are not invariable rules. Judgment changes when a piece of information changes the current $\Delta P$, and usually $\mathrm{CO}$ and $-\mathrm{C}$ $-\mathrm{O}$ increase $\triangle P$ and $\mathrm{C}-\mathrm{O}$ and $-\mathrm{CO}$ decrease it. But information does not always change $\Delta P$. For example, if current $p_{(\mathrm{e} /-\mathrm{c})}$ (probability of the effect occurring in the absence of the cause) $=-1$ and $-\mathrm{CO}$ information is presented, no change in $\Delta P$ will occur, because $p_{(\mathrm{e} /-\mathrm{c})}$ is still -1 . However, the models incorporating $\Delta P$, such as the Power PC theory, never predict decrease following cell $a$ or $d$ and never predict increase following cell $b$ or $c$ information.

2. The models are not intended as literal descriptions of processes, however. Cheng (1997) referred to a distinction drawn by Marr (1982) between computational level issues (what function is being computed by a process) and algorithmic level issues (the goal and constraints that motivate the process): Both are distinct from the issue of how the function is computed. The Power PC theory is a computational model that "seeks to specify the abstract function relating the input and output of the process of causal induction given the constraints that govern the problem of causal induction" (Cheng, 1997, p. 370), and the R-W model is an algorithmic model.

3. Associative models tend to predict recency effects, so that more extreme judgments would be expected in the late conditions than in the early conditions. The results did not conform to these expectations. However, trial order in the critical blocks of trials was not randomized, so it is possible that there was an effect of the particular fixed order of trials used that obliterated the expected recency effect. The results, therefore, do not count either for or against associative models.

4. In principle, the same kind of analysis could be carried out on data from Experiment 1 . However, the sample size of idiosyncratics in that experiment was too small for meaningful statistical comparison. 


\section{APPENDIX \\ Orders of Trials, Experiment 1}

There were four conditions in Experiment 1. In two conditions with $\Delta P=+.17$, a block containing a high proportion of $\mathrm{CO}$ trials occurred either early (Trials 1-8) or late (Trials 17-24). In two conditions with $\Delta P=-.17$, a block containing a high proportion of $\mathrm{C}-\mathrm{O}$ trials occurred either early (Trials $1-8$ ) or late (Trials 17-24). For the remaining trials, $\Delta P=0 .-\mathrm{CO}$ and $-\mathrm{C}-\mathrm{O}$ trials occurred in the same ordinal positions in all conditions. The following table summarizes the presentation order information.

\begin{tabular}{|c|c|c|c|c|}
\hline \multirow[b]{2}{*}{ Trial No. } & \multicolumn{2}{|c|}{$\Delta P=+.17$} & \multicolumn{2}{|c|}{$\Delta P=-.17$} \\
\hline & Early & Late & Early & Late \\
\hline 1 & $\mathrm{CO}$ & $\mathrm{C}-\mathrm{O}$ & $\mathrm{C}-\mathrm{O}$ & $\overline{\mathrm{CO}}$ \\
\hline 2 & $\mathrm{CO}$ & $\mathrm{CO}$ & $\mathrm{C}-\mathrm{O}$ & $\mathrm{C}-\mathrm{O}$ \\
\hline 3 & $-\mathrm{C}-\mathrm{O}$ & $-\mathrm{C}-\mathrm{O}$ & $-\mathrm{C}-\mathrm{O}$ & $-\mathrm{C}-\mathrm{O}$ \\
\hline 4 & $\mathrm{CO}$ & $\mathrm{C}-\mathrm{O}$ & $\mathrm{C}-\mathrm{O}$ & $\mathrm{CO}$ \\
\hline 5 & $\mathrm{CO}$ & $\mathrm{CO}$ & $\mathrm{C}-\mathrm{O}$ & $\mathrm{C}-\mathrm{O}$ \\
\hline 6 & $-\mathrm{CO}$ & $-\mathrm{CO}$ & $-\mathrm{CO}$ & $-\mathrm{CO}$ \\
\hline 7 & $\mathrm{CO}$ & $\mathrm{C}-\mathrm{O}$ & $\mathrm{C}-\mathrm{O}$ & $\mathrm{CO}$ \\
\hline 8 & $\mathrm{CO}$ & $\mathrm{C}-\mathrm{O}$ & $\mathrm{C}-\mathrm{O}$ & $\mathrm{CO}$ \\
\hline 9 & $\mathrm{C}-\mathrm{O}$ & $\mathrm{CO}$ & $\mathrm{CO}$ & $\mathrm{C}-\mathrm{O}$ \\
\hline 10 & $-\mathrm{C}-\mathrm{O}$ & $-\mathrm{C}-\mathrm{O}$ & $-\mathrm{C}-\mathrm{O}$ & $-\mathrm{C}-\mathrm{O}$ \\
\hline 11 & $\mathrm{CO}$ & $\mathrm{CO}$ & $\mathrm{C}-\mathrm{O}$ & $\mathrm{C}-\mathrm{O}$ \\
\hline 12 & $\mathrm{C}-\mathrm{O}$ & $\mathrm{C}-\mathrm{O}$ & $\mathrm{CO}$ & $\mathrm{CO}$ \\
\hline 13 & $\mathrm{CO}$ & $\mathrm{CO}$ & $\mathrm{C}-\mathrm{O}$ & $\mathrm{C}-\mathrm{O}$ \\
\hline 14 & $\mathrm{C}-\mathrm{O}$ & $C-O$ & $\mathrm{CO}$ & $\mathrm{CO}$ \\
\hline 15 & $\mathrm{C}-\mathrm{O}$ & $\mathrm{CO}$ & $\mathrm{CO}$ & $\mathrm{C}-\mathrm{O}$ \\
\hline 16 & $-\mathrm{CO}$ & $-\mathrm{CO}$ & $-\mathrm{CO}$ & $-\mathrm{CO}$ \\
\hline 17 & $\mathrm{CO}$ & $\mathrm{CO}$ & $\mathrm{C}-\mathrm{O}$ & $\mathrm{C}-\mathrm{O}$ \\
\hline 18 & $\mathrm{CO}$ & $\mathrm{CO}$ & $\mathrm{C}-\mathrm{O}$ & $\mathrm{C}-\mathrm{O}$ \\
\hline 19 & $-\mathrm{CO}$ & $-\mathrm{CO}$ & $-\mathrm{CO}$ & $-\mathrm{CO}$ \\
\hline 20 & $\mathrm{C}-\mathrm{O}$ & $\mathrm{CO}$ & $\mathrm{CO}$ & $\mathrm{C}-\mathrm{O}$ \\
\hline 21 & $\mathrm{CO}$ & $\mathrm{CO}$ & $\mathrm{C}-\mathrm{O}$ & $\mathrm{C}-\mathrm{O}$ \\
\hline 22 & $-\mathrm{C}-\mathrm{O}$ & $-\mathrm{C}-\mathrm{O}$ & $-\mathrm{C}-\mathrm{O}$ & $-\mathrm{C}-\mathrm{O}$ \\
\hline 23 & $\mathrm{C}-\mathrm{O}$ & $\mathrm{CO}$ & $\mathrm{CO}$ & $\mathrm{C}-\mathrm{O}$ \\
\hline 24 & $\mathrm{CO}$ & $\mathrm{CO}$ & $\mathrm{C}-\mathrm{O}$ & $\mathrm{C}-\mathrm{O}$ \\
\hline
\end{tabular}

(Manuscript received July 22, 1998;

revision accepted for publication April 30, 1999.) 